with advice on matters as diverse as public transport and nuclearwaste disposal.

There is an opportunity, in the rapidly developing polities of modern Africa, for similar academies to emerge there. The existing academies have had little influence. They were not involved, for example, in shaping the New Partnership for Africa's Development (NEPAD), an important collaboration between Africa's governments whose plans include the creation of research centres and networks to tackle continent-wide woes, such as malaria and poor water supply.

This lack of clout has been equally apparent at the national level. In 2002, for example, when Zambia decided to reject food aid from the United States on the grounds that it contained genetically modified maize, its president Levy Mwanawasa appealed on television for the country's scientists to help him out. The broadcast was the first Zambia's science academy knew of his interest, as there was no established channel for communication between the academy and his government in Lusaka.

There is no good reason why this state of affairs should persist. Academies are not particularly expensive to run, and they already exist in many African countries. Although their membership is small and their expertise is in many cases limited, there are areas in which they could be helping their respective governments right now. What is often missing are the political skills needed to get such advice heard, in government or in the media.

The participants in the National Academy's ten-year project, supported by $\$ 20$ million from the Bill \& Melinda Gates Foundation, are already showing the way ahead, particularly with regard to health issues. In Uganda, for example, scientists will be trained to work effectively with media outlets to get their message across, and regular meetings will be arranged between researchers, businesses, government officials and politicians to discuss their responses to malaria.

For this model to make headway, of course, political leaders need to be convinced of its value. That will only happen in nations with leaders who are genuinely accountable to their electorates, and where a reasonably free press permits public discussion of the issues.

Progress on both these fronts remains patchy, but scientists can strengthen their prospects of being heard by working to build up the effectiveness of their own academies, while finding proactive means of getting their message out to politicians, the media and the wider public. Greater expertise will then be
"Determination from scientists to maketheir voices heard could go a long way towards bringing their expertise to bear on African problems." brought to bear, particularly with regard to pressing African issues, such as standards in education at all levels.

Even in the best of circumstances, it is extremely difficult to get politicians to listen to independent scientific advice. African capitals do not enjoy the best of circumstances. Yet the political situation in many of these capitals is fluid, and determination from scientists to make their collective voices heard could go a long way towards bringing their expertise to bear on African problems.

\section{NASA in reverse}

\section{The US space agency's relationship with scientists is hitting a new low.}

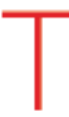

he NASA public-affairs office has this month been accused of trying to censor one of its most eminent climate researchers, James Hansen of the Goddard Institute for Space Studies in New York. And more evidence of press releases being doctored for political ends at the space agency is likely to emerge, disturbing everyone who values the free flow of scientific information to the public.

But the Hansen debacle is just one element of the increasingly adversarial relationship that is developing between NASA and the research community. The sour mood was apparent at last month's American Astronomical Society meeting in Washington DC, when NASA's science chief Mary Cleave told assembled scientists that her most important "stakeholders" were the White House and Congress. Cleave's real (if unintentional) message was clear: don't expect NASA to advocate research, as we work for other interests.

Scientists were also dismayed at how fast NASA administrator Mike Griffin reneged on a promise made last autumn not to take "one thin dime" from space science to address the budget problems of the space shuttle and the space station. At his budget news conference on 6 February, Griffin confessed to doing just that, shifting $\$ 2$ billion over five years from research to the astronaut programme.

The cuts to science were deep, and they were decided behind closed doors. Take the research and analysis grants that fund the basic intellectual work underlying NASA's space missions. Previous NASA administrators, recognizing that many space scientists rely on these grants to stay in business, kept the grant programme healthy. But the new budget slashes research grants by $15-25 \%$, and by even more in areas such as astrobiology. And NASA is yet to give details of how deep the cuts actually are.

Nor did the agency bother to inform some scientists that their projects were being axed. One investigator who was awaiting final approval of her NuSTAR Explorer mission after two years of hard work heard Cleave announce its cancellation at a press conference. Such a cavalier approach to communication is prompting outrage in the community.

NASA is undergoing a historic shift in direction without
"NASA is undergoing a historic shift in direction without consulting scientists or paying attention to their advice." consulting scientists or paying attention to their advice. Projects with great appeal to scientists and to the public - including the search for planets around other stars and the study of dark energy - are being abandoned so that NASA can return astronauts to the moon half a century after the Apollo landings.

Griffin still enjoys some good will from researchers who know him. They understand that his overall budget is set by the White House, and that he is only cutting science reluctantly. But that good will is soon going to vanish if the Bush administration continues to steer the nation's $\$ 17$-billion space programme on such a controversial course, without listening to alternative views of what NASA should be doing. 